\title{
"SER APOLÍTICO ES COMO SER NONATO, DIFUNTO U ORATE”. EMILIA PRIETO Y SU NOCIÓN DE POLÍTICA
}

\author{
Ruth Cubillo Paniagua
}

\begin{abstract}
RESUMEN
En este artículo se realiza un breve recorrido por algunos de los ensayos publicados en la primera mitad del siglo XX por Emilia Prieto Tugores en las siguientes revistas culturales y publicaciones periódicas costarricenses: Repertorio Americano, Diario La Tribuna y Semanario Trabajo. Dicho recorrido permitirá acercarse a los ensayos publicados por esta intelectual costarricense, con el fin de conocer cuáles eran sus principales preocupaciones en el ámbito de la política, el arte y la literatura, entre otros temas, y cuál fue su contribución al pensamiento latinoamericano de la primera mitad del siglo XX.

Palabras clave: Literatura costarricense, Emilia Prieto, ensayos, vanguardia.
\end{abstract}

\begin{abstract}
This article offers a brief review of some of the published essays of the first half of the 20th century by Emilia Prieto Tugores in the following Costa Rican cultural newspapers and journals: Repertorio Americano, Diario La Tribuna y Semanario Trabajo. This review provides the opportunity to get to know the works of this Costa Rican intellectual with the final goal of knowing what were his principle preoccupations with the total scope of politics, art, and literature among other topics, as well as understand his contributions to Latin American thought of the first half of the 20th century.

Key words: Costa Rican Literature, Emilia Prieto, essays, vanguardism.
\end{abstract}

\section{A manera de introducción}

Este trabajo forma parte de un proyecto de investigación inscrito en la Escuela de Filología, Lingüística y Literatura de la Universidad de Costa Rica, titulado "Las intelectuales costarricenses de la vanguardia en la primera mitad del siglo XX. Las ensayistas”. En dicho proyecto nos interesa analizar el pensamiento de las intelectuales costarricenses de vanguardia, en su mayoría mujeres escritoras que publicaron principalmente en la primera mitad del siglo XX. En concreto, nos centraremos en los textos de Carmen Lyra, Emilia Prieto, Luisa González, Lilia Ramos, Ángela Acuña, Yolanda Oreamuno, Eunice Odio y Emma Gamboa.

Dra. Ruth Cubillo Paniagua. Profesora de la Escuela de Filología, Linguística y Literatura y del Posgrado en Literatura Universidad de Costa Rica. Máster en Literatura Latinoamericana por la U.C.R. y doctora en Literatura por la Universidad Autónoma de Barcelona. 
Podríamos pensar en estas mujeres como las "modernas" de San José, en tanto que fueron excepcionales para su época debido a que pudieron insertarse en una cultura y en una sociedad ya no definidas exclusivamente por el género masculino, pues ellas se encargaron de opinar y de escribir sobre temas que, por lo general, habían estado reservados a la competencia de los varones, con lo cual lograron generar un espacio para ser escuchadas y tomadas en cuenta.

La mayoría de estas mujeres "modernas" o "de vanguardia" se desviaron del camino aceptable para las damas de su época: noviazgo, matrimonio, maternidad y vida hogareña; lo hicieron con el fin de buscar nuevos horizontes donde poder desempeñarse como seres pensantes.

Los géneros literarios que trabajaron las "modernas" de Costa Rica fueron varios; entre ellos, y en primer lugar, la lírica, pero además, la narrativa y el ensayo. Ha sido un lugar común pensar que la mujer que se dedica a la escritura debe preferir el cultivo de ciertos géneros, aquellos que le sirvan para expresar mejor su ternura, su sensibilidad y su dulzura. La poesía fue por años el género elegido para ello, de manera que muchas autoras publicaban poemarios repletos de versos dulces y los críticos literarios derrocharon ríos de tinta refiriéndose a esa primorosa y conveniente ternura femenina expresada en tales textos. Cierto es también que algunas mujeres escribieron una poesía diferente, si se quiere más subversiva y atrevida, pero en tales casos los críticos estuvieron atentos para interpretar sus poemarios de manera tal que esa transgresión resultara invisibilizada o, al menos, minimizada.

Si revisamos la presencia de mujeres escritoras en los géneros narrativos (novela y cuento), notamos rápidamente un descenso en el número de autoras; mientras que cuando pasamos al campo del ensayo, ocurre un fenómeno interesante. Las historias literarias, tanto las costarricenses como las centroamericanas, nos han hecho creer por años que en estas latitudes prácticamente no hubo mujeres ensayistas (basta con revisar, para el caso de Costa Rica, la Historia de la literatura costarricense, de don Abelardo Bonilla; el libro de Luis Ferrero sobre los ensayistas costarricenses y alguna otra cosa), pues el ensayo se define como un género en el que se articulan ideas y se produce pensamiento, por lo cual sería más propio de autores que de autoras (por aquello de que las mujeres sentimos más de lo que pensamos).

Sin embargo, si acudimos, por ejemplo, a las revistas culturales que circularon en nuestro país durante la primera mitad del siglo XX, así como a las publicaciones periódicas de esa misma época, rápidamente nos enteramos de que muchas mujeres costarricenses, centroamericanas y latinoamericanas publicaron allí sus ensayos, en los cuales abordaban temas diversos, tales como educación, política, crítica literaria e identidad nacional, entre otros.

Nos interesa ahora realizar un breve recorrido por algunos de los ensayos publicados en la primera mitad del siglo XX por Emilia Prieto Tugores, precisamente en estas revistas culturales y publicaciones periódicas costarricenses, en concreto: Repertorio Americano, Diario La Tribuna y Semanario Trabajo. Este recorrido nos permitirá acercarnos a los ensayos publicados por esta intelectual costarricense, con el fin de conocer cuáles eran sus principales preocupaciones en el ámbito de la política, el arte y la literatura, entre otros temas, y cuál fue su contribución al pensamiento latinoamericano de la primera mitad del siglo XX. 


\title{
2. La inevitable "politicidad" del ser humano
}

\begin{abstract}
(...) La mujer de hoy, no es ya sólo la que borda y cuida de sus hijos, la que ríe en su casa... La mujer ha adquirido derechos que antes no tenía, pero sobre todo y por todo debe seguir siendo la mujer.

(...) el día en que la mujer esté a la par del hombre en el plano político, habrá dejado de ser ella para ser él... Si quiere abarcar bajo su poder lo que hasta hoy han sido derechos del hombre, no podrá cumplir con su misión primordial, la de educar...

La política no se ha hecho para la mujer... la que quiera sentarse en las sillas del Congreso, la que quiera vivir esa vida agitada y pujante de la política, que selle las puertas de su casa y anule su personalidad. La mujer no puede ni debe tener los mismos derechos políticos que el hombre (Eco Católico. Vol. 3. № 27. 1932).
\end{abstract}

Qué distante de esta concepción de LA mujer (recordemos a Jacques Lacan cuando dice que no existe LA mujer, con ese artículo definido que implica que solo existe una manera correcta de ser mujer y es aquella que el falogocentrismo ha determinado como tal) como un ser cuya función primordial consiste en educar (hijos ajenos o propios), pero manteniéndose al margen de los derechos que "por naturaleza" le pertenecen al hombre, entre ellos el derecho a participar y opinar en el ámbito político; qué distante de esta concepción reductora y marginalizante se encuentra la percepción de Emilia Prieto acerca de lo que es la política y acerca de la participación de la mujer en ella.

En 1936, a escasos cuatro años de la publicación del número del Eco Católico que acabamos de citar, nuestra autora acude al escritor español Ramón José Sender para definir en sus palabras lo que es la política:

\footnotetext{
Según Sender, 'saludar a un conocido es ya política y hasta cierto punto lo que no responda exclusivamente a las 3 o 4 necesidades corporales es hacer política. Sólo no son políticos la piedra, el árbol, la estrella. Lo que vive sin conciencia de sí ni de lo que lo rodea'. Pero esto, que convendría tener tan presente, es lo que todos olvidan ("Edwin Piscator: teatro político alemán". Trabajo. Agosto de 1936).
}

Sin duda, Prieto compartía esta forma de entender la política, al punto de que, al repasar someramente sus ensayos, nos percatamos con rapidez de que casi cualquier tema que ella abordaba era atravesado en algún momento por su lanza ideológica-política. Daremos algunos ejemplos. En su artículo titulado "Arte indígena", nos habla en primera instancia de un metate maravilloso que se hallaba en el Museo Nacional, objeto que doña Emilia se dedica a describir y analizar con ojos de crítica de arte; sin embargo, en determinado momento realiza un corte en el texto (que incluso enmarca con líneas de puntos) y señala:

\footnotetext{
Revisando lo nuestro cronológicamente viene la conquista. Todas esas almas dueñas de sus tierras y sus medios, -soberanas y creadoras- fueron sojuzgadas porque encarnaron en cuerpos de indios indefensos, menos aguerridos y numerosos que los otros, los aztecas, mayas e incas. Con la colonia el mestizaje y con la opresión, esclavitud y servidumbre (Repertorio Americano. Junio de 1932).
}

En otro artículo que titula "La octava exposición de Artes Plásticas", aprovecha la ocasión para explicitar claramente su convicción de que el arte y la política no pueden desligarse y por eso critica con dureza a los pintores costarricenses, quizá en alusión más directa a los pintores de la burguesía, liberales de derecha, con la vida resuelta y cero de conciencia social, que solo se preocupan por lo estético y se olvidan del contenido de sus pinturas: 


\begin{abstract}
Nuestros pintores se mantienen empeñados en lo objetivo, buscando dentro de ese expreso propósito efectos de color y forma en un enfoque meramente estético. Es el drama de la época, es el 'dolor profundo entre las penas sin nombres', lo que nos induce a creer inaudito que a la miseria se la matice con las magnificencias del arco iris para exaltar fría e impávida la 'belleza' de una desgarradora e injusta realidad. Surge entonces ya, aquí, ahora y con apremio, una ineludible e incidente condición de actitud y de conciencia. Una nueva dimensión subjetiva (Repertorio Americano. Agosto de 1936).
\end{abstract}

Más adelante, alude con mayor detalle y concreción a esa relación, para ella ineludible, entre arte y política:

Es inconcebible que el lenguaje universal del Arte se niegue a comunicar hondas verdades de la conciencia. Si a él van, como al mar las fuentes inquietas de los ideales humanos y si es la política el único y exclusivo campo donde el hombre en sociedad puede plantear el orden, el método y la táctica para realizar sus anhelos, cuán desolada hoy esa pregunta de ¿qué es el Arte Político? que nos hacen los dómines. Preocupados ellos por sutilezas y matices se quedan plantados como la mujer de Putifar asiendo lo indumentario entre las manos (...) Y por lo visto, aún tendremos que afrontar mucha estética, muchos devaneos sobre la belleza pura, inmóvil e inorgánica -sobre la obra bella, no buena, no dinámica (...) (Ibid).

La poesía tampoco se escapa de esta estrecha ligazón con la política, aunque en este caso Prieto advierte que está pisando en terreno fangoso, puesto que entran en litigio "lo bello" y "lo político". Señala la autora que para analizar esta cuestión se situará necesariamente en la concepción moderna "en cuanto a que las palabras no tienen valor absoluto y que no pueden cerrarse dentro de un sentido intransigente". Aunque el artículo en cuestión se publicó en 1938, nos parece que doña Emilia insinúa, con estas premisas teóricas "modernas", un acercamiento a la noción de texto literario (más cercana a Bajtín y Barthes) más que a la noción de obra literaria. No obstante, ello parece ser solo una ilusión que se desvanece rápidamente, en especial cuando apunta que la poesía es producto del doble espíritu que posee el poeta: el espíritu de la época en que le tocó vivir y el espíritu de sí mismo. Ese poeta es, desde su punto de vista, un ser que sabe encontrar la belleza y posee la facultad de expresarla artísticamente.

Emilia Prieto también fue crítica de cine y en los tres artículos que he analizado en los cuales se dedica a esta labor ("De regreso de la novela 'Después' de Eric María Remarque", 1938; "La vida de Zolá en la pantalla”, 1938; y "Gulliver en el país de los enanos”, 1940, todos publicados en Repertorio Americano) también encontramos presente lo político, pues en los tres casos su análisis se centra en aspectos relativos a las implicaciones políticas de las películas o bien de los personajes o de los textos que las motivan.

Esta ineludible necesidad que tenía doña Emilia de ligarlo todo con la política se resume muy bien en un artículo que publicó en el diario La Tribuna en 1946, el cual se titula "Ser apolítico es como ser nonato, difunto u orate". Para esta autora, la neutralidad es una posición insostenible e inaceptable, de manera que, desde su punto de vista, siempre debemos tomar partido, posicionarnos, opinar. Con esto critica a ciertos intelectuales de su época que preferían mantenerse al margen de los asuntos políticos por considerarlos demasiado terrenos y, por tanto, alejados de sus etéreas ocupaciones.

Al respecto señala Prieto:

Es inexplicable la neutralidad en las personas que por su preparación y cultura deben saber que históricamente, esas condiciones determinantes de que ellos sean sabiondos e ilustres no bajaron del cielo, sino que son el resultado de arduas luchas y memorables conquistas. De ahí que empeñarse en ser apolítico tiene mucha semejanza con proclamarse nonato, difunto u orate en cuanto a responsabilidad y actitud ante los problemas sociales, o equivale a militar hipotéticamente en la política del Edén o de los cementerios. 
Y agrega con gran ironía: "No puede haber sindicatos de ángeles, porque se supone que estas entidades celestiales, tienen todos sus problemas de orden personal social definitivamente resueltos por toda una eternidad".

Prieto defiende la unión de los trabajadores con el fin de mejorar sus condiciones de vida, pues considera que esta es la manera adecuada de hacer valer sus derechos de ciudadanos, miembros de una polis, pero señala además: "esto es precisamente POLÍTICA dentro del más alto sentido que puede tener esta palabra". Por lo tanto, para Prieto el apoliticismo no sería más que una "fría mortaja" que sirve para cubrir la indiferencia de los cobardes.

Al parecer, doña Emilia tenía muy claro que el acceso a la vida política se relaciona con la adquisición de poder y, por lo tanto, con la posibilidad de evadir controles impuestos por el sistema social. Permítanme aquí una pequeña digresión teórica en torno al poder. Es imposible pensar en una sociedad en la cual no estén presentes el poder y las luchas que por él se libran, de modo que los individuos no podrían, aunque quisieran, eliminar el poder de la sociedad. Como afirma la politóloga costarricense Ana Sojo: "negar la existencia del poder conduce al oscurecimiento de su actuación. Se trata, entonces, de reconocer el poder como capacidad para la libertad y se deben encontrar formas de acceso a él, al igual que modos de mantenerlo y de compartirlo" (Sojo 1988: 69).

El sistema patriarcal, con su lógica logocéntrica, trata por todos los medios de no dejar espacios vacíos para que quienes no tienen acceso al poder (los llamados grupos marginales o descentrados) continúen sin tenerlo, pues según la lógica de este sistema lo verdaderamente aterrador no es la aparición del desorden, sino la desaparición del orden establecido. Como señala la psicoanalista argentina Frida Saal (1986: 29):

\footnotetext{
(...) el poder se ubica en el registro de los imaginario y en esta articulación de lo simbólico con lo real, es imposible desconocer sus consecuencias en la realidad. En las formas de ejercicio del poder, como dominación y opresión. En las distintas modalidades del sometimiento: de clases, de razas, de grupos, de sexos. Este poder puede o no estar refrendado por el orden jurídico, pero el orden jurídico funciona preservando de derecho las desigualdades existentes ya de hecho.
}

En el discurso de Emilia Prieto se percibe con claridad la voz de una mujer preocupada precisamente por todas esas desigualdades de hecho que los estados con sus sistemas jurídicos preservan de derecho. En este sentido, Prieto alude no solo a la situación desventajosa de la mujer en la sociedad patriarcal, sino también a otras injusticias de orden económico y social que afectan especialmente a ciertos estratos. Por esta razón, son varios los ensayos de la autora que critican duramente al Estado costarricense y sus estructuras. Veamos algunos ejemplos.

En el artículo "Mujeres conscientes y barbarie facista", Prieto enfila sus armas contra ese Estado que se llama liberal (con todo y la noción de progreso que pregonaba) y civilizado, y que sin embargo permite que mujeres y niños, dos sectores de los más desprotegidos, sufran los embates de la pobreza extrema. Al respecto señala:

Puestos ya en el examen de una condición social dada, ningún elemento de juicio nos parece tan sintomático del caos como la situación desesperante de la mujer y el niño. El Estado en que tal horror se produce, no tiene cultura ni gobierno, ni civilización ni tales estadistas flamantes en último análisis, por más que se haya encasquetado, para impresionar, la fachada burocrática de los tres poderes y se ufane con jactancia oficial de sus sabios, maestros, técnicos, pensadores y artistas que ornamentan -como rígidas cariátidestal fachada barroca (Repertorio Americano. 1937). 
Prieto opina que es necesario protestar y expresar la inconformidad con tal estado de cosas, pues solo de esa manera pueden lograrse reivindicaciones; pero además señala que, por ser "la víctima eterna de todos los sistemas opresivos, medievales y oscurantistas", es a la mujer a quien le corresponde protestar y rebelarse en primera instancia, acudiendo a "nuestro sano sentido común y el alto anhelo de justicia y dignidad humana que ha de llevar consigo toda mujer consciente" (Repertorio Americano. 1937). Vale señalar que este es uno de los pocos ensayos en que Prieto se dirige específicamente a las mujeres.

Más adelante, en 1942, doña Emilia publica, también en Repertorio Americano, un ensayo titulado “¿Qué es el 'concho’?”, y allí se dirige contra los burgueses que se dicen cristianos y sin embargo no son capaces de cumplir ni tan siquiera con el mandamiento de amar al prójimo como a sí mismos, con lo cual se placen en la existencia del "concho", del labriego sencillo, del campesino, pero no porque lo valoren positivamente y lo dignifiquen, sino porque le permite reafirmarse en la creencia de que él, señorito burgués, es superior en todos los niveles al "concho ignorante". Al respecto, apunta lo siguiente con un sutil tono sarcástico y contra todo determinismo social:

\footnotetext{
El hombre civil parece solazarse con que en el todo social exista un alto porcentaje de población campesina atrasada, ingenua, supersticiosa e ignorante que lo divierta con su inveterada torpeza y desgarbado desaliño. No comprende que si se es "concho" por razones de ignorancia, no es menos ignaro el burgués seguro y convencido de que la absurda anomalía social campesina tiene que ser una cosa a perpetuidad absoluta, definitiva y fatal, sin remedio ni apelación posible. El burgués no oye la palabra de Dios. Ni puede ver en el labriego humilde otra cosa que burla y menosprecio (Repertorio Americano. Mayo de 1942).
}

Esta misma línea crítica es la que mantiene en el artículo titulado "Hitler", en el cual se refiere a un hombre burgués adinerado, "hombre de pro, de esos que llaman 'magnífica persona', muy legal en los tratos y celoso de sus 'deberes"”, quien embarazó a la joven empleada doméstica de su casa, “sirvienta que nunca será 'de pro', ni magnífica persona y que se verá siempre a palitos para cumplir con la legalidad y los deberes". Este "responsable" hombre nunca brindó apoyo de ningún tipo ni a la madre ni a la niña fruto de su "relación", pero siempre que pudo le expresó su repugnancia y su desprecio a ambas, mientras que a los hijos habidos en matrimonio les dedica todos sus desvelos.

Esta injusticia social, esta desigualdad sin razón aparente, lleva a Prieto a comparar a este hombre, declaradamente antinazi y antifacista, con el mismo Hitler:

\footnotetext{
Quien es capaz de llevar su individualismo a tan feroz manifestación, como es hacer distingos ruines entre criaturas tan entrañadas como son los hijos, ¿no viene a ser -analizándolo bien- la molécula que unida a millones de moléculas congéneres crean, en el vasto campo de lo político, esa monstruosa aberración del nacionalismo discriminatorio racial cuyo más siniestro representante es Hitler? (...) Y así los vemos por acá, indignados contra el Hitler de Alemania sin darse cuenta del Hitler que llevan dentro de sí mismos (Repertorio Americano. 1941).
}

“Por qué esperar que pasen lustros y decenios para juzgar a los políticos?”. Este es el título de otro ensayo de Prieto, publicado en el Semanario Trabajo en 1944, en el cual elogia al Dr. Rafael Ángel Calderón Guardia, precursor de las garantías sociales en Costa Rica, pero también critica al Estado constitucional por creer que bastaba con dejar de ser una colonia y pasar a ser una República independiente, regida por una constitución política, para acabar con la injusticia social, la explotación y la marginación. En este sentido, señala: 
Pero pasan los años y resulta que entre la Constitución escrita y la vida real hay un abismo; que sin libertad económica no hay libertad civil y que en un país de explotadores y explotados no hay igualdad posible. (...) una décima parte de la población recibe los favores municipales o sea los beneficios del progreso: cañería, luz, higiene, etc. El otro noventa por ciento es un conglomerado semibárbaro y desnutrido que se mal alumbra, bebe agua de acequia, se hace recetar del curandero, cree en brujas, anda descalzo, indefenso, expuesto a enfermedades y accidentes. Este caos injusto y cruel se llama Orden (Trabajo. 1944).

\section{A manera de epílogo}

Después de este brevísimo recorrido por los ensayos de Emilia Prieto, maestra, escritora, crítica de arte, de cine y de literatura, grabadista y folclorista costarricense, militante de izquierda y de los movimientos de mujeres, fundadora, en asocio con la Central de Trabajadores de Costa Rica, de la Universidad Obrera y gran activista política en el sentido que ella recuperó para este término, no podemos dejar de pensarla como una de las intelectuales costarricenses de vanguardia que, durante la primera mitad del siglo XX, especialmente en las décadas de 1920 a 1950, cuando el país atravesaba por cambios y crisis de orden político y económico, escribieron sobre temas álgidos, desde una perspectiva que para muchos podía resultar incómoda e incluso peligrosa o transgresora del "orden" establecido; ese orden que, como acabamos de ver, para Prieto era más bien un caos injusto y cruel, dentro del cual perviven explotadores y explotados, victimarios y víctimas, hombres de pro y conchos de pie en el suelo, burgueses adinerados y pobres extremos, un caos dentro del cual la movilidad social se concibe, por parte de quienes detentan el poder, como algo casi imposible y los políticos liberales manejan el doble discurso del progreso y el determinismo social.

Nos preguntamos ahora ¿por qué los textos de Emilia Prieto han permanecido prácticamente sin ser leídos ni difundidos; por qué no forman parte del canon, por qué son dejados de lado por las historias de la literatura y de las antologías de ensayo? Cada quien tendrá su propia respuesta.

\section{Bibliografía citada y consultada}

Cubillo, Ruth. 2001. Mujeres e identidades: las escritoras del Repertorio Americano (19191959). San José: EUCR.

Iglesia Católica Costarricense. 1932. Eco Católico, vol. 3, № 27.

Ovares, Flora y Margarita Rojas. 1995. 100 años de literatura costarricense. San José: Farben Norma.

Prieto, Emilia. 1932. “Arte indígena”, Repertorio Americano.

1936a. "Edwin Piscator: teatro político alemán”. Trabajo y Repertorio Americano.

1936b. "La octava exposición de artes plásticas". Trabajo.

1937. "Mujeres conscientes y barbarie fascista". Repertorio Americano. 
1938a. "De regreso a la novela 'después' de Eric María Remarque". Trabajo y Repertorio Americano.

1938b. "La vida de Zolá en la pantalla". Repertorio Americano.

1938c. "Poesía política". Repertorio Americano.

1940. Gulliver en el país de los enanos". Los Andes, Argentina.

1941. "Hitler". Repertorio Americano.

1942. “QQué es ‘concho’?”. Repertorio Americano.

1944. “Por qué esperar que pasen lustros y decenios para juzgar a los políticos?”. Semanario Trabajo.

1946. "Ser apolítico es como ser nonato, difunto u orate". Diario La Tribuna.

1977. Escritos y grabados. San José: Editorial Costa Rica.

Saal, Frida. 1991. "Algunas consecuencias políticas de la diferencia psíquica de los sexos". En: Saal, D. y M. Lamas (eds.).

Saal, D. y M. Lamas (eds.). 1991. La bella (in)diferencia. México: Siglo XXI.

Sojo, Ana. 1998. Mujer y política, 2a edición, San José: DEI. 